\title{
DUVAL, Raymond. Ver e ensinar a matemática de outra forma: entrar no modo matemático de pensar: os registros de representações semióticas. Organizaçãa de Tânia M. M. Campos. Traduçãa de Marlene Alves Dias. São Paulo: PROEM, 2011.

\author{
Helaine Maria de Souza Pontes* \\ Gabriela Teixeira Kluppel $^{* *}$
}

Raymond Duval é autor da Teoria das Representações Semióticas. Filósofo, psicólogo e professor emérito da Universidade Du Litoral Côrte d’Ópale, desenvolveu importantes pesquisas em Psicologia Cognitiva no Instituto de Pesquisa em Educação Matemática (IREM) de Estrasburgo, no período de 1970 a 1995.

O livro intitulado Ver e ensinar a matemática de outra forma: entrar no modo matemático de pensar: os registros de representaçoes semióticas, de autoria de Raymond Duval, organizado por Tânia Maria Mendonça Campos e traduzido pela professora Marlene Alves Dias, foi publicado pela Editora PROEM no ano de 2011.

A obra está dividida em quatro capítulos. O Capítulo I: "Representação e Conhecimento: a revolução semiótica", traz à baila algumas considerações sobre a importância da primeira análise do conhecimento. Para tanto, discute sobre a diferença intrínseca entre o objeto e sua representação, o surgimento da noção de signo, a distinção entre significante e significado e a relação dos signos com o que eles significam.

Após uma densa e arrazoada argumentação desses aspectos, Duval menciona a origem da operação discursiva intencional de designação e começa analisar os estudos de Husserl.

O autor faz então um breve histórico do surgimento da álgebra, salientando a emergência dos signos e símbolos específicos da matemática. Considera também as conexões entre a escrita das equações com suas representações gráficas.

\footnotetext{
Mestre em Educação pela Universidade Estadual de Ponta Grossa. E-mail: < helainempontes@yahoo. com.br>

** Mestre em Educação pela Universidade Estadual de Ponta Grossa. E-mail: <gabrielakluppel@yahoo. com.br>
} 
Duval coloca que a extensão semiótica das representações modifica a primeira análise do conhecimento. Em seguida, traz um breve histórico sobre o surgimento dos estudos dos signos que foi sistematizado a partir do fim do século XIX, por meio da análise de sua diversidade e da sua função na atividade científica e na comunicação, com os trabalhos de Peirce, Saussure e Frege. Salienta que todos os outros trabalhos que surgiram sobre os signos, tiveram a contribuição destes autores.

Duval alerta para o fato de que os trabalhos de Peirce, Saussure e Frege são muito diferentes, principalmente porque se utilizam de disciplinas distintas para análise dos signos. A seguir questiona sobre qual desses modelos pode ser considerado mais adequado para que as produções dos alunos e as atividades propostas sejam analisadas de forma que se esclareçam o funcionamento semicognitivo. Traz à tona as principais proposições de cada autor, relaciona-as com a compreensão da matemática e aponta as limitações de todas.

Para responder ao questionamento do parágrafo anterior, Duval afirma que esses modelos são inadequados a tudo que é observado no funcionamento e desenvolvimento da atividade matemática. Propõe então que os matemáticos reformulem de forma mais precisa as questões que direcionaram os modelos, apontando uma pergunta para cada um deles.

Afirma que, para responder às três questões que formulou, é necessário adotar um modelo de análise que dê conta de descrever como se dão os processos de compreensão e as causas das dificuldades frequentes na aprendizagem da matemática.

Conclui este capítulo enfatizando sobre a clivagem cognitiva entre signos e representações.

No capítulo II intitulado "Atividade matemática e transformações de representações semióticas", Duval destaca a questão da necessidade de representações semióticas no conhecimento matemático, ao mesmo tempo em que ressalta dois problemas muito diferentes: o primeiro é epistemológico, e o segundo é cognitivo. Esses dois problemas referem-se ao modo de acesso aos objetos matemáticos e aos gestos intelectuais, que caracterizam a atividade matemática.

Diante destes dois problemas Duval faz conjeturas referentes a como reconhecer um mesmo objeto em representações diferentes. Para o autor, representações é a relação complexa na qual o conteúdo da representação depende tanto do tipo de representação mobilizada como do objeto representado. $\mathrm{O}$ autor destaca que o reconhecimento de um mesmo objeto representado por duas representações diferentes repousa sobre a correspondência das unidades de sentido dessas duas representações. 
O autor aponta que, para fazer os alunos entrarem no funcionamento do pensamento matemático, uma das questões que já aparece cognitivamente crucial é como fazer com que se tome consciência do papel central da operação de colocar em correspondência. As operações matemática e cognitiva de colocar em correspondência dizem respeito aos elementos dos conteúdos respectivos de duas representações semióticas.

Duval também discute as transformações das representações semióticas no centro da forma do trabalho matemático. Para o autor um sistema semiótico de representação se caracteriza por suas potencialidades de transformações semióticas, e toma como exemplo os números, para discutir e analisar essas transformações.

No capítulo III intitulado "Registros de representações semióticas e análise do funcionamento cognitivo do pensamento em matemática", Duval retoma algumas questões referentes às transformações, para dar conta dos tipos de transformações, introduz a noção de registro de representação semiótica. Para corroborar a análise toma como exemplo a linguagem e as figuras geométricas.

Inicialmente refere-se aos registros semióticos e ao funcionamento do pensamento. Orienta quanto aos tipos heterogêneos de sistemas semióticos, distingui os códigos e os registros. No tocante aos registros o autor ressalta sua relação com as transformações. Segue explanando a respeito do desenvolvimento do conhecimento.

Em seguida, faz apontamentos quanto ao tipo de atividade de pensamento que requer a utilização da língua natural. Especifica também as operações discursivas: enunciação, designação e expansão discursiva. Expõe a relação entre as operações discursivas e as expressões linguísticas.

Posterior aos apontamentos referentes à língua natural, Duval faz uma explanação detalhada referente às figuras geométricas e suas especificidades em relação aos registros de representações semióticas.

No capítulo IV intitulado "Os registros: método de análise e identificação das variáveis cognitivas", Duval preconiza a importância do reconhecimento das unidades de sentido e a transformação destas unidades, nas produções matemáticas, condições indispensáveis para que seja possível a compreensão. Segue orientando sobre os procedimentos necessários para que possamos descrever o funcionamento cognitivo.

$\mathrm{O}$ autor utiliza as retas ou segmentos de reta nos gráficos lineares para que, a partir de cinco oposições qualitativas, consiga obter em cada uma dois valores visuais distintos, que constituem duas unidades de sentido, de acordo com Saussure. A regra metodológica é inspirada nas ciências experimentais e consiste 
em fazer variar cada fator, mantendo os outros constantes, para que seja possível definir qual dos valores visuais distintos é matematicamente pertinente.

Duval sugere, por razões muito coerentes, que as atividades a serem propostas aos alunos, com vistas à análise cognitiva, devem ser do tipo tarefas de reconhecimento e não de resolução de problemas e propõe que os registros sejam classificados para facilitar a análise.

Discute também sobre os pares de registros mobilizados na atividade matemática, tanto os de tratamentos como os de conversões, salientando a importância desses últimos e trata com o mesmo rigor dos fenômenos de congruência e não congruência.

O autor se apoia em Damm (1992) para indicar as representações auxiliares que facilitam a compreensão dos problemas aditivos.

Traz à tona uma discussão sobre a complexa tarefa de analisar a atividade cognitiva pela distinção de dois aspectos radicalmente diferentes na produção dos indivíduos: os modos fenomenológicos de produção das representações e os diferentes sistemas mobilizados para produzi-los.

Duval aborda o problema das variáveis didaticamente pertinentes pelo método de análise das atividades dadas em classe, assim como das produções dos alunos com idade entre 10 e 11 anos, ao realizarem atividades sobre simetria axial.

Conclui no último capítulo do livro ponderando sobre os aspectos que devem ser considerados nos trabalhos de pesquisas que tratam da compreensão/ incompreensão dos conceitos matemáticos. Enfatiza sobre o cuidado que é preciso ter na coleta e análise de dados, e que as produções dos alunos podem ser analisadas pelo critério matemático ou cognitivo, salientando a importância deste último. $\mathrm{O}$ autor esclarece também como as representações semióticas devem ser analisadas para que a produção matemática possa ser investigada não por princípios teóricos, mas metodológicos.

Cabe evidenciar que essa obra de Duval é muito importante para a distinção de aspectos fundamentais das representações semióticas relacionados ao conteúdo e à forma contemplados nas transformações. Essa distinção coloca em destaque os procedimentos metodológicos necessários para a identificação de variáveis pertinentes em cada registro e a necessária correspondência para que se torne possível a distinção entre o objeto matemático e sua representação e a referência ao mesmo objeto matemático. Não menos importante é o destaque para as representações intermediárias na mediação desse procedimento de natureza cognitiva. 
A grande contribuição dessa obra de Duval refere-se às possibilidades de enfrentamento das dificuldades dos alunos para conceitualizar objetos matemáticos, visto que esses objetos só são acessíveis por meio de suas representações.

\section{Referência}

DAMM, R. Apprentissage des problèmes additifs et compréhension de texte. Thèse ULP. Strabourg: IREM, 1992. 